\title{
Hexose transporters in Trichoderma reesei; structure, function and regulation Bishoy Hanna ${ }^{\dagger 1}$, Augusto Ramos ${ }^{3}$, Felipe S Chambergo ${ }^{2}$, Amira Mahmoud ${ }^{1}$ and Hamza El Dorry*1,2
}

\author{
Address: ${ }^{1}$ American University in Cairo AUC Avenue, P.O. Box 74 New Cairo 11835, Egypt, ${ }^{2}$ Institute of Chemistry, University of São Paulo 748 , \\ São Paulo SP 05508-900, Brazil and ${ }^{3}$ Boston University Boston, MA 02215, USA (Charles River Campus) \\ * Corresponding author †Equal contributors
}

from 2009 American University in Cairo Research Conference

Cairo, Egypt. 5 April 2009

Published: I July 2009

BMC Proceedings 2009, 3(Suppl 3):O3

This abstract is available from: http://www.biomedcentral.com/I753-656I/3/S3/O3

(c) 2009 Hanna et al; licensee BioMed Central Ltd.

Egypt population is about 70 million and grows by an average annual rate of $2.1 \%$. The majority of the Egyptian population lives in Delta region and nearby to the Nile River in Upper Egypt. The populated areas thus have immense population densities. There is very little space available on farms for storage, treatment or processing of agricultural residues. The agricultural residues produced in Egypt reaches about 27 million ton annually. This number is expected to grow as a result of the land reclamation plans by the government, thus producing more agriculture residues. The fungus Trichoderma reesei is well known for its celluloytic capacity, therefore promises a great potential in ethanol production from cellulose based feedstock and agriculture waste management. In order to conduct successful metabolic engineering of Trichoderma reesei we investigate sugar transport mechanisms as a limiting factor to the metabolism of the fungus and the production of metabolites. Glucose transport is the first step toward glucose utilization and despite the availability of the genome sequences of diverse multicellular fungi, including T. reesei, a comprehensive study of their sugar transport systems has not yet been reported. In contrast, the glucose transporters genes of $S$. cerevisiae and their transcriptional control by glucose have been extensively studied. This work aims to cover the structural and functional properties of the hexose transporters in Trichoderma reesei in order to help understanding the steps need to exploit the fungus biotechnologically in ethanol production from cellulosic biomass. 